\title{
Mapping mountain pine beetle infestation with high spatial resolution satellite imagery
}

\author{
by Joanne C. White ${ }^{1}$, Michael A. Wulder ${ }^{2}$, Darin Brooks ${ }^{3}$, Richard Reich ${ }^{4}$, and Roger D. Wheate ${ }^{5}$
}

The on-going mountain pine beetle outbreak in British Columbia has reached historic proportions. Recently, management efforts at the local level shifted from exhaustive mapping of the infestation, to detection and mitigation of sites with minimal levels of infestation, creating an operational need for efficient and cost-effective methods to identify red-attack trees in these areas. High spatial resolution remotely sensed imagery has the potential to satisfy this information need. This paper presents the unsupervised classification of 4 metre IKONOS multispectral imagery, for the detection of mountain pine beetle red-attack, at sites with minimal infestation $(<20 \%$ of trees infested). A 4-metre buffer (analogous to a single IKONOS pixel) was applied to the red-attack trees identified on the IKONOS imagery in order to account for positional errors. When compared to the independent validation data collected from the aerial photography, it was found that $70.1 \%$ (lightly infested sites) and 92.5\% (moderately infested sites) of the red-attack trees existing on the ground were correctly identified through the classification of the remotely sensed IKONOS imagery. These results demonstrate the operational potential of using an unsupervised classification of IKONOS imagery to detect and map mountain pine beetle red-attack at sites with minimal levels of infestation.

Keywords: mountain pine beetle, remote sensing, accuracy assessment, IKONOS, red-attack

L'épidémie de dendroctone du pin actuellement en cours en Colombie-Britannique a atteint des proportions historiques. Dernièrement, les efforts d'aménagement au niveau local se sont dirigés de la cartographie exhaustive de l'épidémie vers la détection et la mitigation sur les sites connaissant des niveaux minimes d'épidémie, créant ainsi un besoin au niveau des opérations de méthodes rentables d'identification des arbres très atteints dans ces sites. L'imagerie de télédétection à haute résolution spatiale pourrait répondre à ces besoins d'information. Le présent article fait état de la classification non supervisée de l'imagerie multispectrale de 4 mètres IKONOS, utilisée pour la détection d'attaque massive de dendroctone du pin sur des sites d'épidémie légère (<20\% des arbres infectés). Une zone tampon de 4 mètres (analogue à un pixel individuel d'IKONOS) a été appliquée aux arbres très atteints identifiés par l'imagerie IKONOS de façon à tenir compte des erreurs de position. Lorsque les données furent comparées aux données indépendantes de validation recueillies à partir de photographies aériennes, on a constaté que 70,1\% (sur les sites d'épidémie légère) et 92,5\% (sur les sites d'épidémie moyenne) des arbres très atteints retrouvés au sol avaient été correctement identifiés suite à la classification de l'imagerie de télédétection IKONOS. Ces résultats soulignent le potentiel opérationnel de l'utilisation de la classification non supervisée de l'imagerie IKONOS pour détecter et cartographier les pics d'infestation du dendroctone sur des sites connaissant des niveaux minimes d'épidémie.

Mots-clés : dendroctone du pin, télédétection, évaluation de la précision, IKONOS, attaque maximale

The on-going mountain pine beetle outbreak in British Columbia has reached historic proportions. From 2002 to 2003, the area infested with mountain pine beetle doubled, increasing from approximately 2.0 million hectares to 4.2 million hectares. The extent of the current mountain pine beetle outbreak, the rapid rate of the infestation's spread, and the associated economic impacts, have prompted research into new techniques and data sources for reconnaissance and mapping of the infestation. Detection and mapping of attacked trees serves to delineate and document the current impact of the infestation, enabling planning and mitigation activities. In addition, knowledge of current impact serves as a driver in parameterizing models of beetle spread that are designed to reduce future risks and impacts. Recently, management efforts at the local level have shifted from exhaustive mapping of the infestation, to the detection and mitigation of sites with minimal levels of infestation. The motivation behind this shift in management focus has been to identify new pockets of infestation, and thereby reduce or contain the outbreak to a size and distribution that may be handled within the capacity of the existing forest industry infrastructure.

Trees in the red-attack stage of infestation have a distinctive red colour, which facilitates their detection with remote sensing instruments (Fig. 1). Although the timing of the different stages of infestation is somewhat variable amongst individual trees, the general progression of foliage discoloration is predictable. Under typical conditions, adult mountain pine beetles attack trees in mid-summer, and lay eggs that develop into mature adults approximately one year later (the beetles must attack in large numbers to overcome the defences of a healthy tree and this is referred to as mass-attack). Once killed, but still with green foliage, the host tree is in the green-attack stage. The foliage of the host tree changes gradually and twelve-months after being attacked, over $90 \%$ of the killed-trees will have red needles (red-attack). Three years after being attacked, most trees will have lost all needles (grey-attack).

\footnotetext{
${ }^{1}$ Canadian Forest Service, Pacific Forestry Centre, 506 West Burnside Road, Victoria, British Columbia V8Z 1M5. Email: joanne.white@ nrcan.gc.ca

2 Canadian Forest Service, Pacific Forestry Centre, 506 West Burnside Road, Victoria, British Columbia V8Z 1M5. Email: mwulder@nrcan.gc.ca. Author to whom correspondence should be sent.

${ }^{3}$ Kim Forest Management Ltd., 1985 Garden Drive, Prince George, British Columbia V2M 2V9. E-mail: kfmgis@telus.net

${ }^{4}$ British Columbia Ministry of Forests, 1011 4th Avenue, Prince George, British Columbia V2L 3H9. E-mail: Richard.Reich@ gems4.gov.bc.ca

${ }^{5}$ University of Northern British Columbia, Natural Resources and Environmental Studies, 3333 University Way, Prince George, BC, V2N 4Z9. E-mail: wheate@ unbc.ca
} 

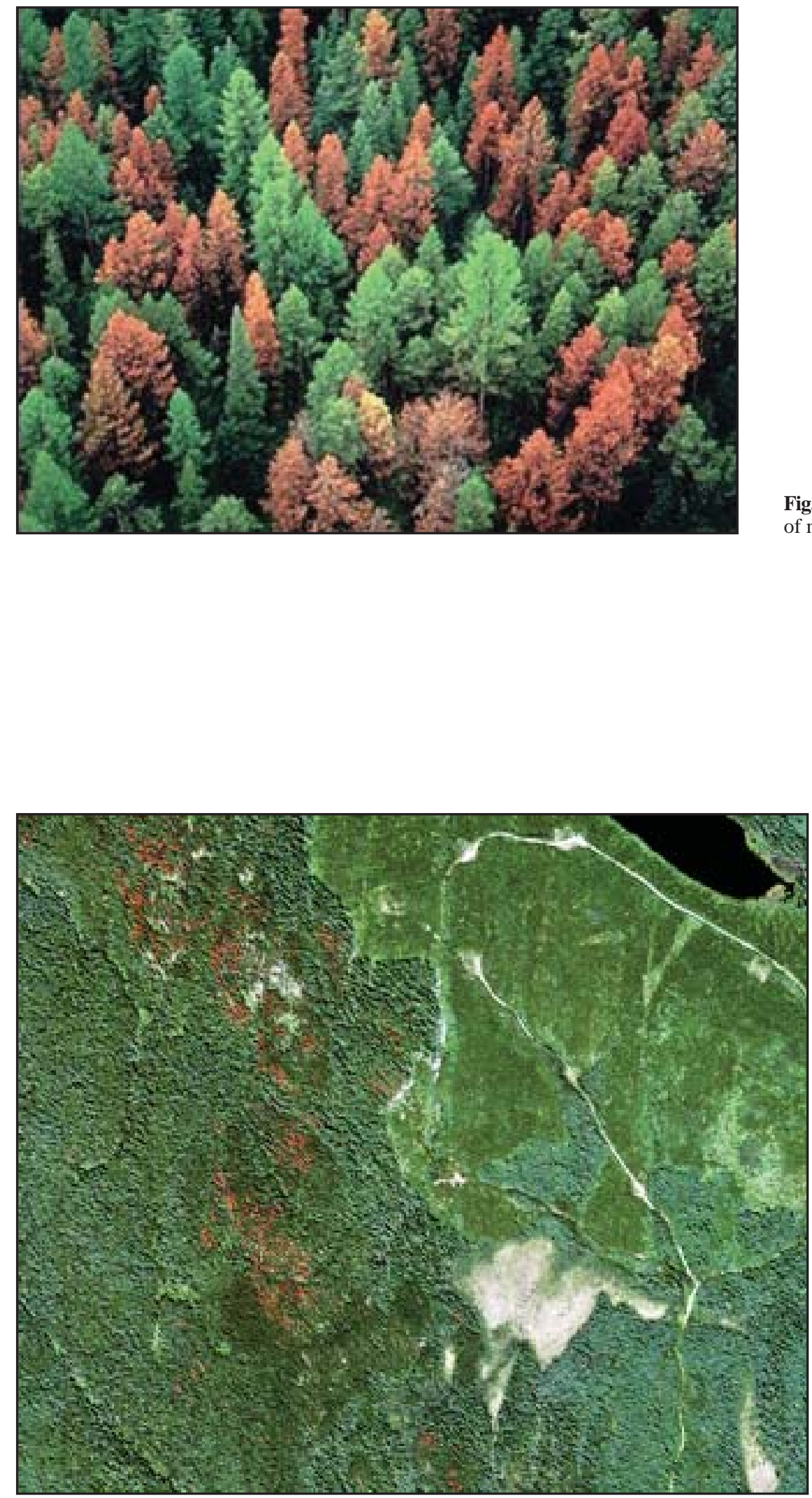

Fig. 1. An example of trees at the red-attack stage of mountain pine beetle infestation.
Fig. 2. Sub-sample of the IKONOS 4 metre multispectral imagery (covering an area approximately $2.15 \mathrm{~km}$ by $1.75 \mathrm{~km}$ ). Mountain pine beetle red attack trees are visible in the western portion of the image. 

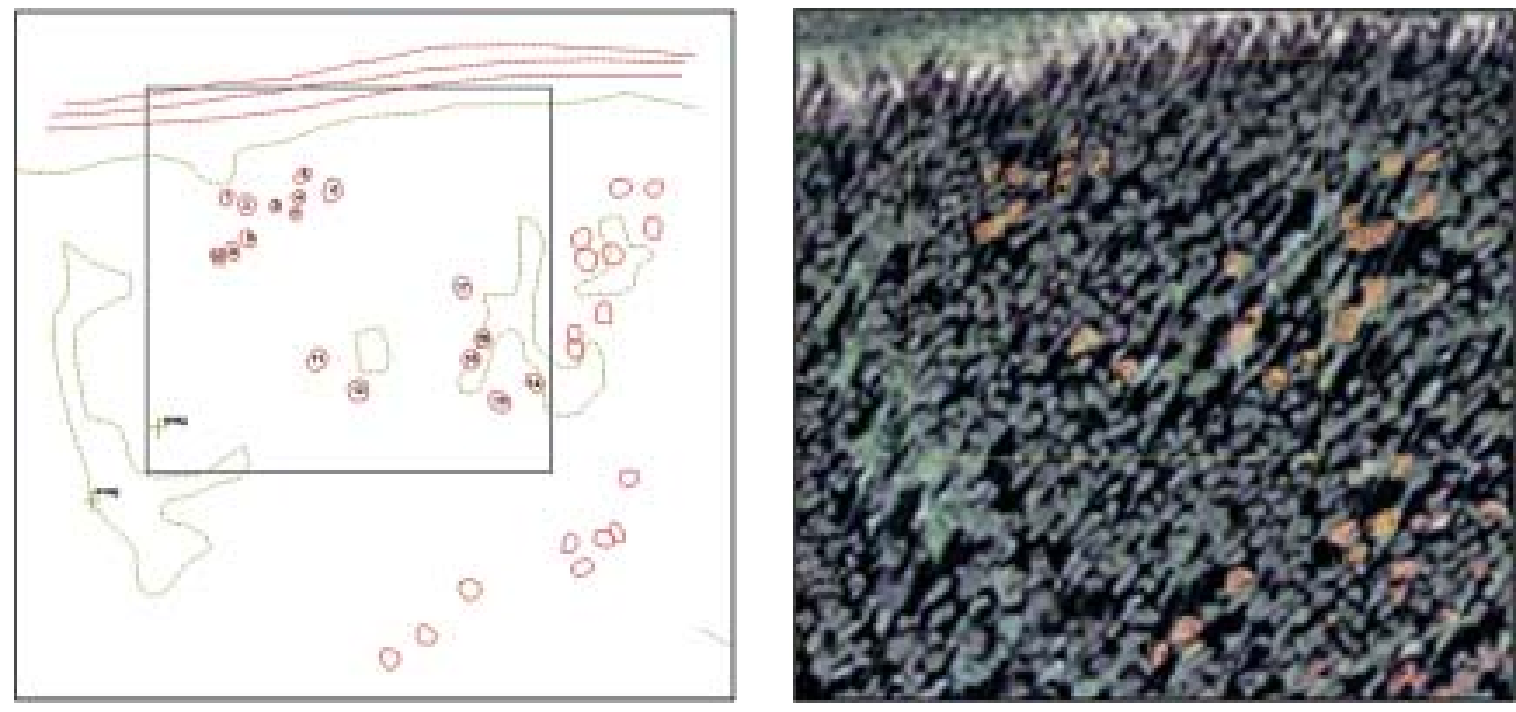

Fig. 3. Detailed stem map (left) generated from 1:30 000 scale colour aerial photography (right).

Researchers are currently investigating the use of high resolution remotely sensed data for detecting and mapping mountain pine beetle red-attack trees.

The availability of commercially delivered, high spatial resolution satellite data offers a potential source for the costeffective collection of accurate, consistent, and timely data regarding mountain pine beetle impacts. Furthermore, the use of imagery for this scale of red-attack mapping provides a permanent record of the survey, which can subsequently be used by field crews who need to assess not only the exact location of the red-attack, but also the extent and shape of the red-attack stands and their relative position in the landscape. Successful feature extraction from remotely sensed data entails trade-offs between object size and the appropriate scale of information, and this tradeoff is often manifested in the image resolution. High spatial resolution remotely sensed data provides a promising option for the detection of red-attack at both local and landscape scales. The imagery has a high level of spatial detail, yet its spatial extent is greater than that of a 1:30 000 aerial photograph. For instance, the spatial extent of IKONOS and QuickBird images are 121 and 272.25 square kilometres, respectively, compared to 47 square kilometres for a 1:30 000 photo. Unsupervised classification algorithms may be used to isolate red-attack.

An investigation into the merits of using one such high resolution remotely sensed data source (IKONOS 4-metre multispectral data, Fig. 2) was recently completed at a study site near Prince George, British Columbia. This project examined the use of an unsupervised clustering of 4-metre IKONOS multispectral imagery for the detection of mountain pine beetle red-attack at susceptible sites (i.e., with known risk factors for infestation) which were considered to be lightly infested ( $1 \%$ to $5 \%$ of trees red-attacked) or moderately infested (greater than 5\% and less than 20\% trees red-attacked). Independent calibration and validation data were collected from 1:30 000 scale aerial photography, and these data were used to assess the accuracy of the resulting red-attack map (Fig. 3). A 4-metre buffer (analogous to a single IKONOS pixel) was applied to the red-attack tree identified on the IKONOS imagery in order to account for positional errors. When compared to the independent validation data collected from the aerial photography, it was found that $70.1 \%$ (lightly infested sites) and $92.5 \%$ (moderately infested sites) of the red attack trees existing on the ground were correctly identified through the classification of the remotely sensed IKONOS imagery. Analysis of red-attack trees that were missed in the classification of the IKONOS imagery indicated that detection of red-attack was most effective for larger tree crowns (diameter > 1.5 metres) that were less than 11 metres from other red-attack trees. These results demonstrate that unsupervised classification of mountain pine beetle red-attack using IKONOS imagery is an operationally useful approach.

This project was completed as a result of collaboration between the Canadian Forest Service, the British Columbia Ministry of Forests, the University of Northern British Columbia, and Kim Forest Management Ltd. (KFM), where KFM undertook the data collection, photo interpretation, and the subsequent image analysis. This work was funded by the Province of British Columbia's Forestry Innovation Investment Program and by Canadian Forest Products Ltd. Elements of this project were funded by the Government of Canada through the Mountain Pine Beetle Initiative, a six-year, $\$ 40$ million program administered by Natural Resources Canada, Canadian Forest Service (http://mpb.cfs.nrcan.gc.ca).

The methods and results presented in this communication are fully described in a paper presently under review for publication in the journal Remote Sensing of Environment. For more information about this project, contact Darin Brooks at Kim Forest Management Ltd. 1985 Garden Drive, Prince George, BC, V2M 2V9; 250-564-3808; kfmgis@telus.net 